Review

\title{
The role of dietary flavonoids for modulation of ATP binding cassette transporter mediated multidrug resistance
}

\author{
Hui Teng ${ }^{1}$, Hongting Deng ${ }^{1}$, Yuanju $\mathrm{He}^{1}$, Qiyan $\mathrm{Lv}^{1}$, Lei Chen ${ }^{11, *}$ \\ ${ }^{1}$ College of Food Science and Technology, Guangdong Ocean University, Guangdong Provincial Key Laboratory of Aquatic Product Processing \\ and Safety, Guangdong Province Engineering Laboratory for Marine Biological Products, Guangdong Provincial Engineering Technology \\ Research Center of Seafood, Key Laboratory of Advanced Processing of Aquatic Product of Guangdong Higher Education Institution, \\ Zhanjiang 524088, China
}

A R T I C L E I N F O
Article History
Received 18 October 2021
Accepted 6 December 2021
Keywords
Bioavailability
Intestine
Flavonoids
ATP binding cassette $(\mathrm{ABC})$
transporter

\begin{abstract}
A B S T R A C T
Flavonoids are widely existing compounds with enormous pharmacological effects from food and medicine. However, the low bioavailability in intestinal absorption and metabolism limits their clinical application. Intestinal efflux ABC (ATP binding cassette) transporters, including P-glycoprotein (P-gp), breast cancer resistance protein (BCRP) and multidrug resistanceassociated proteins (MRPs), act as "pumping doors" to regulate the efflux of flavonoids from intestinal epithelial cells into the intestinal cavity or the systemic circulation. The present review describes the critical effect of $A B C$ transporters involved in the efflux of flavonoids which depend on its efflux direction. And the role of flavonoids for modulation of intestinal ABC transporters was emphasized and several examples were given. We summarized that the resistance effect of flavonoid-mediated multidrug on $\mathrm{ABC}$ transporters may influence the bioavailability of drugs, bioactive ingredients and/or toxic compounds upon dietary uptake. Meanwhile, flavonoids functionalized as reversing agents of the $\mathrm{ABC}$ transporter may be an important mechanism for unexpected food-drug, food-toxin or food-food interactions. The overview also indicates that elucidation of the action and mechanism of the intestinal metabolic enzymes-efflux transporters coupling will lay a foundation for improving the bioavailability of flavonoids in vivo and increasing their clinical efficacy.
\end{abstract}

(C) 2021 The Authors. Publishing services by Visagaa Publishing House This is an open access article distributed under the CC BY-NC 4.0 license (https://creativecommons.org/licenses/by/4.0/).

\section{INTRODUCTION}

Flavonoids distinguished by the main chemical structure of C6C3-C6, are a class of polyphenols widely existed in food and other natural products. They have a variety of biological activities, such as antioxidant, anti-inflammatory, anti-virus, and anticancer effects. The instability of flavonoids in the intestinal is one of the reason for their low bioavailability, limiting their clinical application [1] . In recent years, the intestinal absorption and biotransformation characteristics of flavonoids have drawn extensive attentions. In general, flavonoids are metabolized by three phase II drugmetabolizing enzymes, including glucuronide transfer UDP glucuronosyltransferases (UGTs) [2], sulfatases (SULTs) [3], and glutathione S-transferases (GSTs) [4]. Subsequently, these phase II metabolites are transported by ATP binding cassettes Porter (ABC) located in the apical membrane of intestinal epithelial cells to the intestinal cavity or into systemic circulation, including P-glycoprotein (P-gp), mammary gland Cancer resistance protein (BCRP), and multidrug resistance associated protein (MDR-associated proteins, MRPs), etc. significantly affect the pharmacokinetics, drug interactions and clinical efficacy and side effects of flavonoids [5]. Studies have shown that phase II metabolites are the main form of flavonoids that existed in vivo, while phase I drug metabolizing enzymes, alike cytochrome P450 (CYP) and etc., play a weak role in the internal disposal for flavonoids [6]. But it can be significantly affected by the efficient coupling of drug metabolizing enzymes with efflux transporters [7]. Recently published studies focusing on the coupling effect of phase I drug metabolizing enzyme of (CYP3A4)P-gp, showed that the P-gp had a regulatory effect on CYP3A4 metabolism, and synergistically affected the pharmacokinetics and pharmacodynamics of drugs [8-10]. And our research group has recently found that there was an important coupling between phase II drug metabolizing enzymes (UGTs, sults) and efflux transporters (BCRP, MRPs), which significantly affected the in-vivo disposal of flavonoids $[1,11]$. In this review, we summarized relative findings regarding the $\mathrm{ABC}$ transporters involved in the efflux of flavonoids from the intestinal cells to the basolateral blood side and thereby facilitating absorption, or back into the intestinal lumen, leading to reduced bioavailability.

${ }^{*}$ Corresponding author. Email: chenlei841114@hotmail.com

Peer review under responsibility of the International Association of Dietetic Nutrition and Safety 


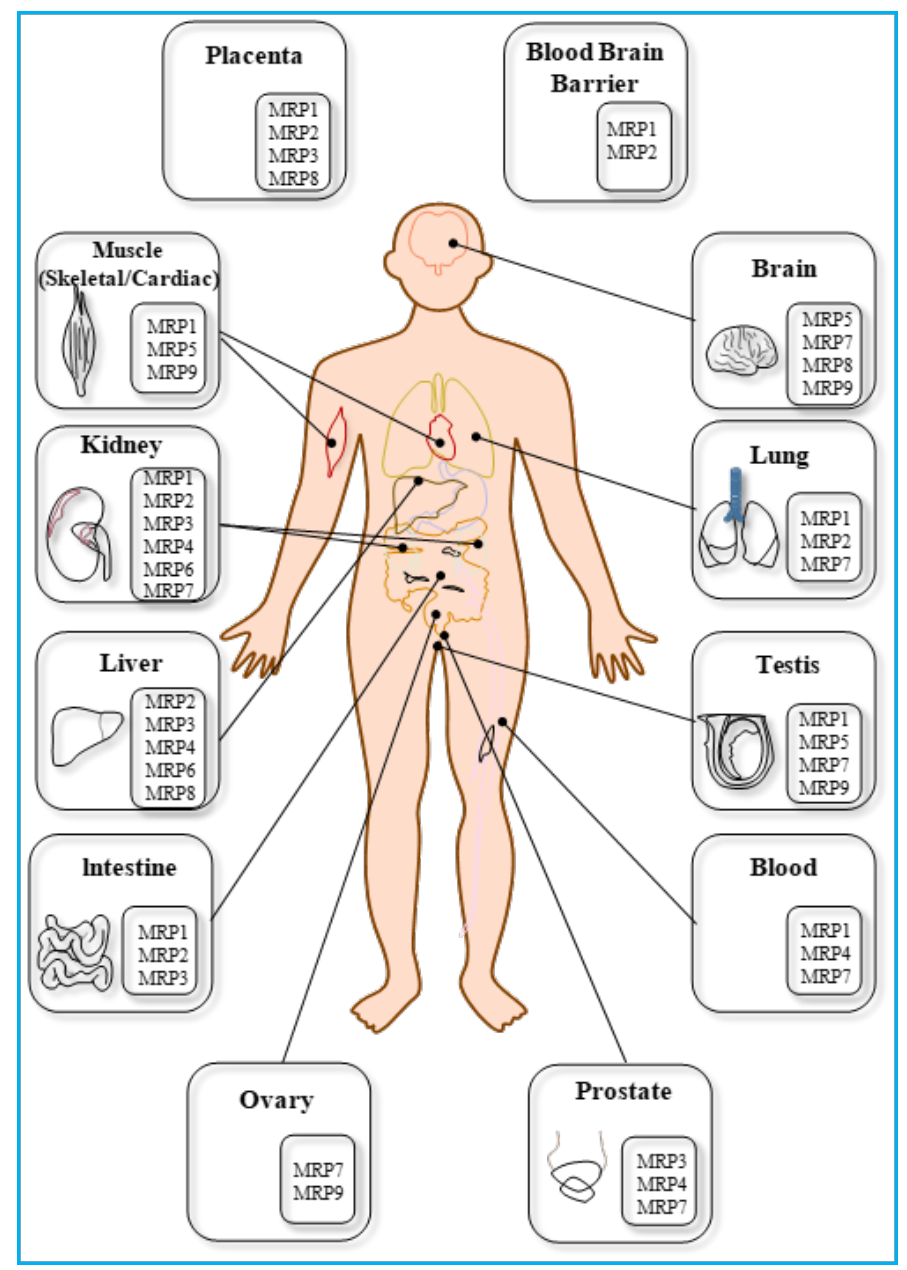

Figure 1 Distribution of MRPs in major human tissues and organs (Adapted from Wang et al., 2021).

\section{CORRELATION BETWEEN ABC TRANSPORTERS AND MDR}

The intestinal ABC transporters including P-gp (P-glycoprotein), MRPs (multidrug resistance proteins) and BCRP (breast cancer resistance protein) are involved in the efflux of chemicals [12]. These transporters are generally located specifically in the apical (intestinal luminal side) or basolateral (blood/plasma side) membrane of the enterocytes (Figure 1). Drugs could be simultaneously substrated and/or inhibited with more than one efflux transporter, indicating that these transporters exert a combined detoxification role in the intestine [13]. Among all of the ABC transporters, P-gp and MRPs have been extensively studied in controlling the efflux and uptake of many chemicals such as phenolics, nutrients, amino acids, inorganic ions, and etc. $[14,15]$. Examples for the involvement of P-gp and MRPs in the bioavailability of phytochemicals and bioactive compounds can be found in literatures [16-18]. Several researchers conducted in-vitro studies and supported the role of $\mathrm{ABC}$ transporters in the absorption of drug at the gastrointestinal tract through monolayers of cultured Caco-2, HCT8, and MDCK epithelial cells [19-21]. Other in vivo works also demonstrated the P-gp played an important part in reducing the oral bioavailability of several drugs, such as digoxin [22], talinolol [23], cyclosporine [24] and vinblastine [25]. And the result for the intestinal uptake of cyclosporine was also confirmed by healthy human [26]. More efficient transportation of saquinavir was found in MRP2transfected MDCK II cells (Madin-Darby canine kidney), when compared to other MDCKII cells over-expressed ABC transporters, indicating a vital role of MRP2 in the efflux of saquinavir [27]. On the other hand, pharmacokinetic studies by Merino and co-workers [28] reported that the concentration of fluoroquinolone antibiotic ciprofloxacin in the plasma of deficient BRCP1 (-/-) mice was increased more than twofold $(1.77 \mu \mathrm{g} / \mathrm{ml})$, after the oral administration of ciprofloxacin in $10 \mathrm{mg} / \mathrm{kg}$ dose, as compared with wild-type mice $(0.73 \mu \mathrm{g} / \mathrm{ml}, \mathrm{p}<0.01)$. This result suggested that the BCRP1 constrained the oral bioavailability of ciprofloxacin [28]. Meanwhile, the oral bioavailability of topotecan could also be affected by BRCP1 and P-gp transporters in mice [29]. In a study of co-administrated humans with GF120918, which was an inhibitor of BCRP and P-gp, the bioavailability of topotecan was increased as well [30]. In addition to the role of $\mathrm{ABC}$ transporters in the oral bioavailability of drugs, recent studies have focused on their roles in determining the bioavailability of toxins, bioactive compounds, and food ingredients [31, 32]. For example, 2-amino-1-methyl6-phenylimidazo pyridine (PhIP) known as the major toxic heterocyclic amine in cooked meat, has been demonstrated to be transported back into the lumen by apical $\mathrm{ABC}$ transporters, when the $\mathrm{ABC}$ transporters acted as the first line of defense against this harmful compound [31]. The interaction between ABC transport proteins and $\mathrm{PhIP}$ was also investigated by using multiple model systems, including Caco-2 monolayers with specific inhibitors of Pgp- or MRP-associated transport proteins [33], MRP2 deficient rats [34], MRP2 knockout mice [35], and Bcrp1(-/-) mice [34]. Data obtained by Walle and co-workers from an in vitro Caco-2 cell monolayers system showed that MRP2 played a role in the transport of genistein-7-glucoside, and therefore resulted in a low bioavailability (Walle et al., 2003). The same system was employed for the transport studies of Ginkgo flavonols, and it was demonstrated that quercetin, kaempferol, and isorhamnetin were substrates for P-gp and that Pgp-mediated efflux [36]. Using the specific BCRP1 inhibitor of fumitremorgin C, in situ intestinal perfusion MRPs deficient rats and MDCKII cells, it was confirmed that especially Bcrp1 limited the absorption of quercetin from intestinal of the flavonoid [37]. In fact, the culture cells model, everted intestine, and the whole animal system are extensively used experimental methods for the evaluation of intestinal efflux transporters located on an apical membrane (Figure 2).

\section{FLAVONOIDS REGULATE ABC TRANSPORTERS TO OVERCOME MDR}

Phytoestrogen genistein has been demonstrated to modulate P-gp expression in hepatocellular carcinoma in vitro, moreover, it was found effective in the clearance of relevant P-gp substrates at concentrations as tested by (author?) [38]. In mouse macrophages J774.1, nobiletin activated AMPK and promoted the expression of ABCA1 and ABCG1 [39]. Tangeretin, a citrus pentamethoxyflavone, antagonized ABCB1-mediated multidrug resistance by inhibiting its transport function [40]. The effects of 


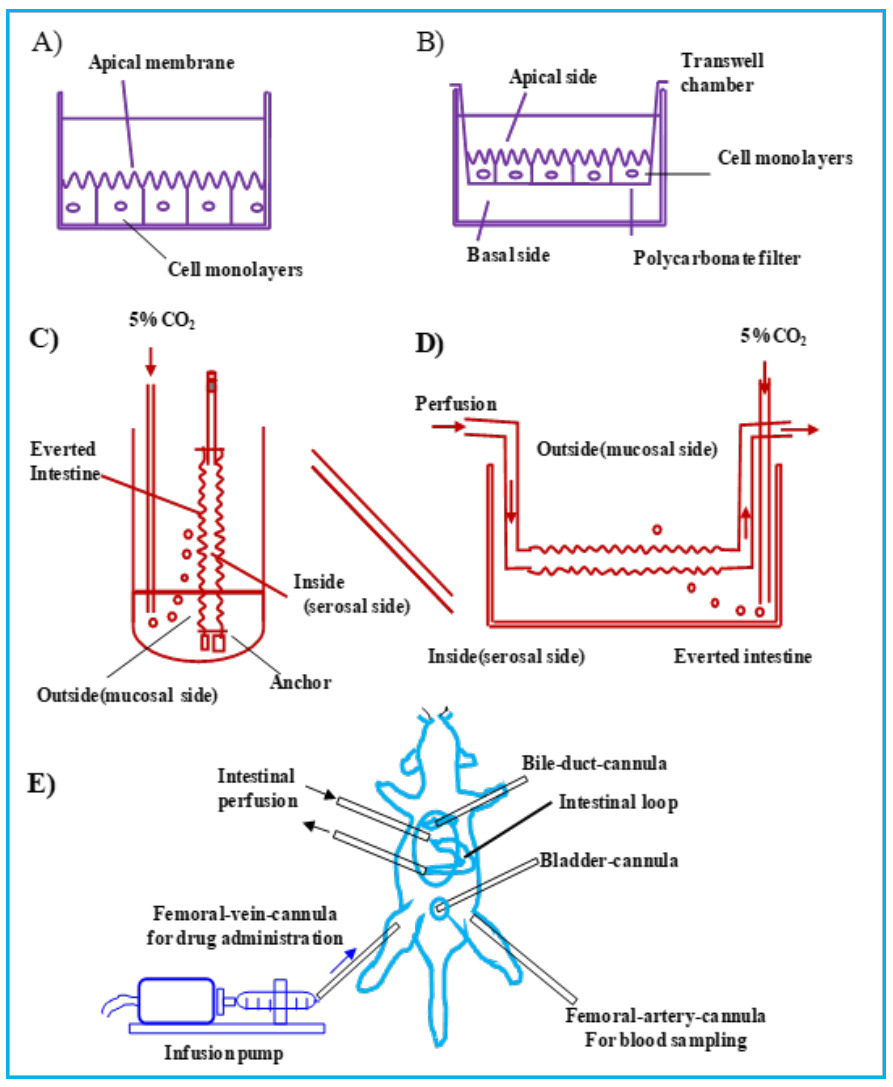

Figure 2 Schematic representation of some experimental methods for the functional analysis of intestinal efflux transporters located on apical membrane: culture cells $(A, B)$, everted intestine $(C, D)$, and whole animal (E), adapted from Takano et al [13] .

CG, EC, EGC, ECG, and EGCG on the P-gp function in multidrugresistant P-gp over-expressed KB-C2 cells were observed by many researchers as shown in Table 2. Apigenin and naringenin with $\mathrm{C} 2=\mathrm{C} 3$ conjugation were proved to down-regulate $\mathrm{ABC}$ transporter expression, and inhibit P-gp activity and ATPase [41]. Ali and co-authors found that pre-treatment with naringin at 5 $\mathrm{mg} / \mathrm{kg}$ body weight for 3 consecutive days, was able to inhibit the doxorubicin-stimulated ATPase activity and modulate the in vivo expression of P-gp [42]. The modulatory effect of acacetindoxorubicin complex on the influx and efflux of doxorubicin was mediated through down-regulation of MDR1 transporter in NSCLC cells [43]. On the other hand, chrysin could inhibit ABCB1 mediated rhodamine 123 (an ABCB1 substrate) efflux in human breast cancer MDA-MB-231 cells [44]. Chrysin might also regulate ABCG2 mediated nitrofurantoin transport on ABCG2overexpressed human MCF-7 breast cancer cells by increasing the area under the curve (AUC) [45]. Moreover, chrysin sensitized the ABCG2-transfected cells to mitoxantrone (an ABCG2 substrate) via stimulating ATPase [46]. Naringenin seemed to use an active ATP system mediated by MRP1, which was expressed at the basolateral side of the intestinal cell [47]. Daidzein $(5 \mu \mathrm{M})$ could up-regulate MRP2- and down-regulate MRP1 protein expressions in MCF-7 and MDA-MB-231 cells, respectively. Major findings from both in vitro and in vivo studies revealed that the quercetin was an MDR modulator [48]. Biochanin A and phloretin have been

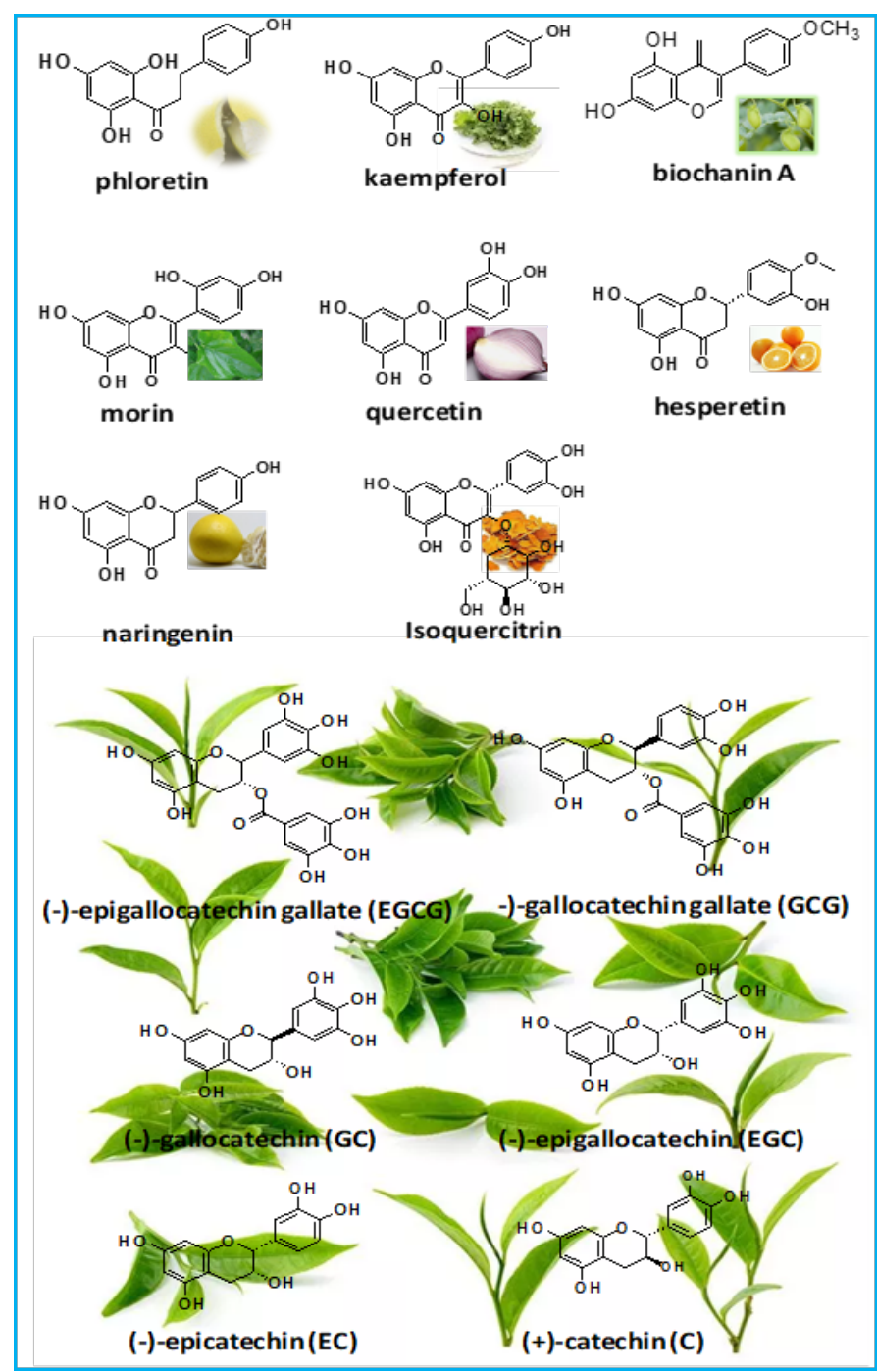

Figure 3 Chemicalstructure of some P-glycoprotein inhibitors belonging to flavonoids (PubChem Compound Database)

reported to have the ability to stimulate P-gp ATPase activity [49], however, morin and silymarin showed an inhibitory effect on P-gp, confirming that all of them could inhibit P-gp-mediated cellular efflux [50]. This review summarized the variety of flavonoids with an overlapped specificity for P-gp, MRPs, and BCRP as shown in Figure 4. Biochanin A, kaempferol hesperetin, and quercetin have been reported many times for their similar activities on $\mathrm{ABC}$ transporters, which indicated that the structural characteristics for the inhibition of the three major human $\mathrm{ABC}$ transporters( P-gp, BCRP and MRP2) may be partly similar. However, knowledge gained so far for the affinity overlap between $A B C$ transporters has been only derived from scattered observations for individual compounds or small series [51,52]. Therefore, more systematic studies on affinity patterns and molecular features of flavonoids that determine the inhibition specificity of $\mathrm{ABC}$ transporters are of great interest in future researches. 
Table 1 Overview the effect of dietary flavonoids on transport or bioavailability of drugs and other xenobiotics in different model systems

\begin{tabular}{|c|c|c|c|}
\hline Flavonoids & Model system & $\begin{array}{l}\text { Accumulation of target } \\
\text { compound }\end{array}$ & References \\
\hline Genistein & $\begin{array}{l}\text { Caco-2, IEC-6, MDR1-MDCK, } \\
\text { HCC-derived HepG2 cells }\end{array}$ & Repaglinide, Daunorubicin & {$[53,54]$} \\
\hline $\begin{array}{l}\text { Morin, phloretin, biochanin } \\
\text { A, chalcone, and silymarin }\end{array}$ & MCF-7/ADR cells & Daunomycin & [55] \\
\hline Nobiletin & $\begin{array}{l}\text { ABCB1 over-expressing A2780/T } \\
\text { and A549/T, KB-C2 , Caco-2 }\end{array}$ & $\begin{array}{l}\text { Paclitaxel, doxorubicin, docetaxel, } \\
\text { dounorubicin, daunorubicin, } \\
\text { vinblastine }\end{array}$ & {$[56,57]$} \\
\hline $\begin{array}{l}\text { Baicalein, } \\
\text { (-)-epigallocatechin gallate, } \\
\text { kaempferol, quercetin and } \\
\text { silymarin }\end{array}$ & MDCK II & Rhodamine 123 & [58] \\
\hline $\begin{array}{l}\text { Catechin-gallate, } \\
\text { epigallocatechin-gallate, } \\
\text { epicatechin-gallate }\end{array}$ & MDCK-MDR1 cells & $\begin{array}{l}\text { Antiepileptic drugs: } \\
\text { carbamazepine, phenytoin, } \\
\text { oxcarbazepine }\end{array}$ & [58] \\
\hline Curcumin & $\begin{array}{l}\text { MCF\&\#8209;7/DOX, } \\
\text { MDA\&\#8209;MB\&\#8209;231/DOX }\end{array}$ & Doxorubicin & [59] \\
\hline Quercetin, & Rats & Rhodamine 123 & {$[60]$} \\
\hline $\begin{array}{l}\text { Acacetin, apigenin, chrysin, } \\
\text { diosmetin, genistein, } \\
\text { kaempferide, kaempferol, } \\
\text { luteolin, } \\
\text { luteolin-4'-O-glucoside, } \\
\text { naringenin, } \\
\text { naringenin-7-glucoside }\end{array}$ & K562, K562/BCRP & Mitoxantrone, SN-38, topotecan & {$[61]$} \\
\hline Tangeretin & $\begin{array}{l}\text { Adriamycin resistant } \\
\text { human myelogenous leukemia }\end{array}$ & $\begin{array}{l}\text { Vincristine, verapamil, cyclosporin } \\
\text { A }\end{array}$ & {$[62]$} \\
\hline Daidzein & LS-180V Cells & rhodamine-123 & [63] \\
\hline Biochanin- & Panc- 1 cells. & Daunomycin, vinblastine & {$[64]$} \\
\hline \multicolumn{4}{|c|}{$\begin{array}{l}\text { A, genistein, quercetin, chalcone, silymarin, phloretin, morin, } \\
\text { and kaempferol }\end{array}$} \\
\hline $\begin{array}{l}\text { Biochanin A, quercetin, } \\
\text { silymarin }\end{array}$ & MCF-7, MCF-7 ADR & Daunomycin & [49] \\
\hline $\begin{array}{l}\text { Apigenin, biochanin A, } \\
\text { chrysin, diosemin, fisetin, } \\
\text { genistein, hesperitin, } \\
\text { kaempferol, luteolin, morin, } \\
\text { narigenin, phloretin, and } \\
\text { quercetin }\end{array}$ & MDA-MB231 & $\gamma$-hydroxybutyrate & [65] \\
\hline $\begin{array}{l}\text { Flavonoid derivatives } \\
\text { possessing } \mathrm{N} \text { - } \\
\text { benzylpiperazine } \\
\text { chain }\end{array}$ & K562/DOX cells & Doxorubicin & [66] \\
\hline Myricetin & Caco-2 & $\begin{array}{l}\text { 2-amino-1-methyl-6- } \\
\text { phenylimidazo[4,5-b]pyridine }\end{array}$ & {$[67]$} \\
\hline
\end{tabular}




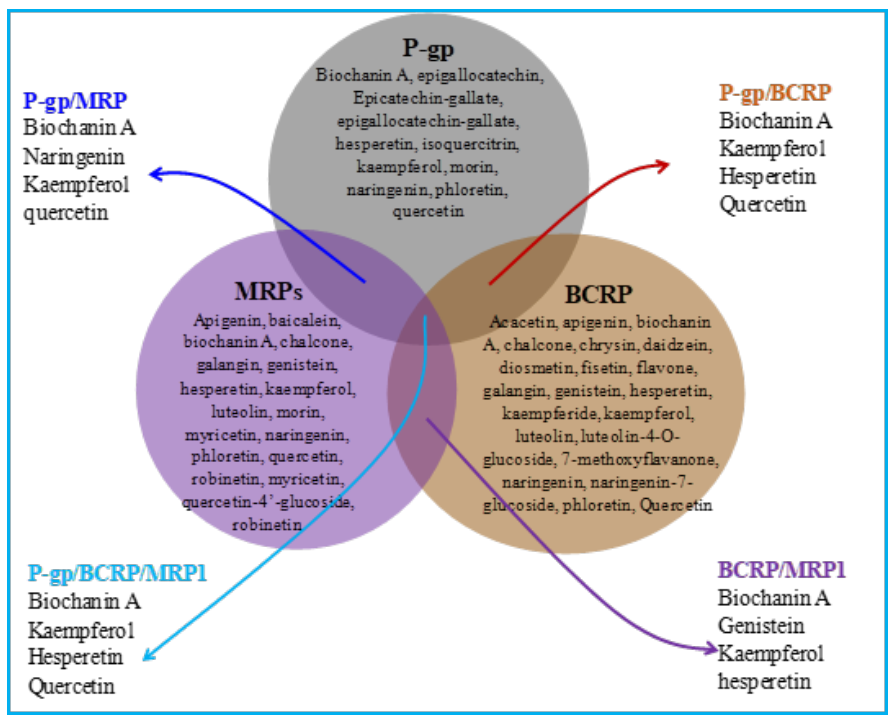

Figure 4 A varieties of flavonoids with an overlapped specificity for Pgp, MRPs, and BCRP.

\section{FLAVONOIDS EFFECT ON ACCUMULATION AND BIOAVAILABILITY OF BIOACTIVE COMPOUNDS}

By given the involvement of transport proteins in the efficiency of intestinal transport, it can be envisaged that the $\mathrm{ABC}$ transport inhibitors may not only affect the MDR of tumor cells, but may also affect the bioavailability of diverse drugs, bioactive food ingredients and/or toxic compounds upon oral uptake (Table 1). For instance, Jin et al. found that exposure to genistein elicited an elevation in intracellular accumulations of Rhodamine 123 and daunorubicin (DNR) in P-gp-expressing cell lines [43]. Intestinal absorption of repaglinide was found predominantly enhanced by genistein or P-gp inhibitor of verapamil (Ver), according to in situ rat jejunal perfusion studies and in vitro transport assays using everted rat intestinal sac preparations [53]. Meanwhile, as P-gp inhibitors, morin, phloretin, biochanin A, chalcone, and silymarin, significantly increased daunomycin accumulation in vitro by more than 2.5-fold [55]. Moreover, it has been reported that nobiletin, a citrus methoxyflavone, could increase the accumulation of daunorubicin in KB-C2 cells and the uptake of vinblastine in Caco-2 cells. In addition, nobiletin significantly sensitized ABC overexpressed cells (A2780/T and A549/T) to paclitaxel, doxorubicin, docetaxel, and dounorubicin [56]. Ferreira and co-authors showed that baicalein, (-)-epigallocatechin gallate, kaempferol, quercetin and silymarin, at $200 \mu \mathrm{M}$, produced a significant enhancement in the intracellular accumulation of rhodamine 123 in MDCK-MDR1 cells potentially through the inhibition of P-gp activity [58]. They also evaluated a selected flavonoid combination of (-)-epigallocatechin gallate/silymarin in transepithelial transport experiments using licarbazepine (the active metabolite of oxcarbazepine) as a model compound, and the results revealed that the combination of (-)-epigallocatechin gallate/silymarin was the most promising one (Ferreira et al., 2018b). Furthermore, curcumin reversed doxorubicin resistance in human breast cancer MCF\&\#8209;7/DOX and
MDA\&\#8209;MB\&\#8209;231/DOX cells by inhibiting the ATPase activity of ABCB4 [59]. Quercetin was another reported inhibitor for P-glycoprotein-mediated efflux transport, exhibiting an enhancement on the intracellular accumulation of rhodamine123 in MCF-7/ADR cells with P-gp overexpressing [60]. Heptamethoxyflavone, nobiletin, and tangeretin, also promoted the uptake of vincristine in a concentration-dependent manner in adriamycin-resistant human myelogenous leukemia cells [62]. On the other hand, at the same concentration level of $100 \mu \mathrm{M}$, biochanin-A, genistein, quercetin, chalcone, silymarin, phloretin, morin, and kaempferol displayed the ability to increase the accumulation of daunomycin and vinblastine in Panc-1 cells [64]. Moreover, biochanin A, silymarin, and naringenin are able to reversethe MDR via inhibiting the P-gp function and increasing the accumulation of daunomycin in MCF-7/ADR cells [49]. Apigenin, biochanin A, chrysin, diosemin, fisetin, genistein, hesperitin, kaempferol, luteolin, morin, narigenin, phloretin, and quercetin significantly altered the pharmacokinetics and pharmacodynamics of $\gamma$-hydroxybutyrate [45]. Fan et al. (2019) investigated the inhibitory effects of 99 flavonoids on BCRP in vitro and in vivo, who clarified certain structure-activity relationships that might exist between flavonoids and BCRP. Eleven types of flavonoids, including amentoflavone, apigenin, biochanin $\mathrm{A}$, chrysin, diosimin, genkwanin, hypericin, kaempferol, kaempferide, licochalcone A and naringenin, exhibited significant inhibition against BCRP in BCRP-MDCKII cells, through which the BCRP-mediated effluxes of doxorubicin and temozolomide were reduced (Fan et al., 2019). Moreover, another earlier study demonstrated that 28 flavonoid derivatives, at a concentration of $5 \mu \mathrm{M}$, increased the cytotoxic activity of doxorubicin in resistant K562/DOX cells [68]. Moreover, 2,3,4-trimethoxybenzylpiperazine chain attached to either flavones or flavanone moiety was found to be more potent in reversing the MDR as compared to the standard verapamil [67].

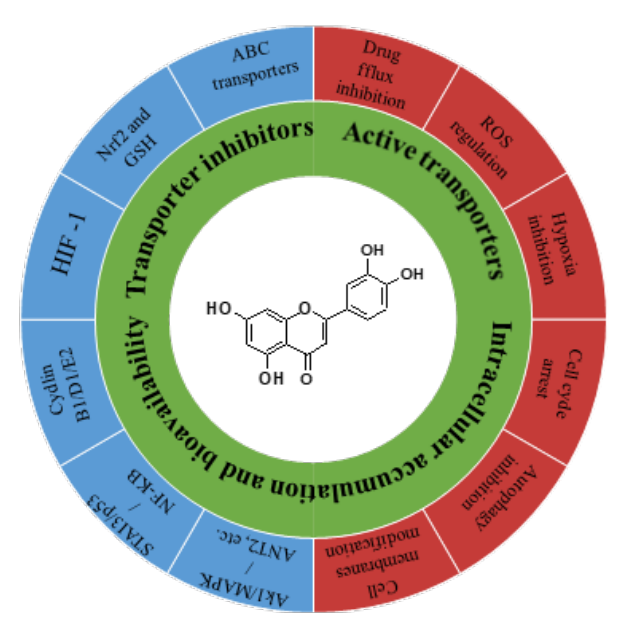

Figure 5 Multi-functional flavonoids in overcoming MDR. 


\subsection{Molecular mechanism of flavonoids regulating $A B C$ transporters}

As in molecular level, the expression of P-gp is usually mediated by multiple pathways, involving CYP3A4, NF- $\kappa \mathrm{B}$, cylooxygenases2 (COX-2), the mitogen-activated protein kinase (MAPK) pathway, and phosphoinositide 3-kinase (PI3K) (Figure 5). Among them, MAPK/ERK and NF- $\kappa \mathrm{B}$ pathways are more reliable based on their molecular mechanisms for MDR inducement. The NF$\kappa \mathrm{B}$ pathway actively responds to MDR1 induction through the activation of $\mathrm{I} \kappa \mathrm{B}$ kinase, the degradation of $\mathrm{I} \kappa \mathrm{B}$, and the generation of reactive oxygen species [69]. Moreover, NF- $\kappa \mathrm{B}$ is bound at the nucleotide position of the MDR1 promoter mediating the transcription of MDR1 [70]. Similarly, the MAPK pathway, which involves in p38MAPK subfamilies, c-Jun NH2-terminal kinase (JNK)/stress-activate protein kinase (SAPK), and extracellular signal-regulated kinase (ERK), also has crucial parts in signals transmission, as provided by various kinds of stimulus to regulate the MDR1 expression. Currently, various studies revealed the over-expression of P-gp seemed to be closely related to the nuclear localization of Y-box binding protein 1(YB-1) in various solid tumors such as osteosarcoma, ovarian cancer, prostate cancer, and breast cancer [71]. In addition, Coles et al verified MAPK/ERK pathway regulated the phosphorylation of YB-1 via ERK phosphorylation [69]. However, the interaction between natural flavonoid agents and MAPK/ERK mediated YB-1 activity has not been well investigated yet.

\section{2. $N F-\square B / I \square B$ signaling pathway}

Under normal physiological conditions, NF- $\mathrm{KB}$ and its antagonistic subunit IкB in cytoplasm will combine to form an inactive complex. When DNA is damaged by hypoxia or chemotherapeutic drugs, ІкB is phosphorylated, and NF- $\mathrm{KB}$ will be released from the complex and enter the nucleus [72]. NF-кB could bind with the first exon of MDR1 promoter region and further start the transcription of MDR1, resulting in MDR [73]. For example, (author?) [69] used A2780 and paclitaxel resistant strain A2780/T to investigate the inhibitory effect of procyanidins on P-gp, and the result indicated that procyanidins could significantly enhance the cytotoxicity of paclitaxel in A2780/T resistant strain, and the procyanidins could also inhibit the expression of P-gp mRNA in time and concentration dependent manners [69]. In a study of signaling pathway, proanthocyanidins significantly inhibited the nuclear transfer of NF- $\mathrm{KB} / \mathrm{p} 65$ induced by LPS and receptor activator for NF-кB ligand (RANKL), and attenuated the up regulation of NF-кB/IкB signaling pathway $[69,74]$. In addition, puerarin also showed a reverse effect on drug resistance. After being treated with puerarin, the content of doxorubicin in K562/ADR resistant strain increased, and the $\mathrm{IC}_{50}$ value of resistant strain decreased from 41.5 to $3.24 \mu \mathrm{M}$, and the expression of MDR1 protein, the activity of NFкB in K562/ADR cells was significantly inhibited [55]. (author?) [75] proved that baicalein and luteolin have the chemoprevention effect and inhibit drug resistance of LoVo/Dx cells, which may be related to the overexpression of P-gp [75]. In addition, (author?) [70] have observed the ability of baicalein to suppress the activation of NF- $\kappa \mathrm{B}$ in the HCT116 cell line. A significant increase in inflammation incidence of the tumor was also found in colon tumors stimulated mice [70]. Furthermore, the survival of colon cancer cells and the stability of their genome were also influenced by baicalein through the reduction of securine level and the increase of $\gamma-\mathrm{H} 2 \mathrm{AX}$ [76]. Taking these evidence together, (author?) [77] concluded that the underlying mechanisms of flavonoids with inhibitory effect on MDR in cancer cells may be due to the inhibition of p65 hydrolysis and ІкB phosphorylation, thereby inhibiting the transcription and expression of MDR1, the target gene of NF- $\mathrm{KB}$, and finally showing a protective effect on the drug resistance of drug-resistant cell lines (Table 2).

\subsection{MAPK signaling pathway}

There are three classical pathways in multicellular mammalian: extracellular signal regulated kinase (ERK), c-jun $\mathrm{NH} 2$ terminal kinase (JNK), and p38 MAPK pathway [86]. In MAPK signaling pathway, ERK pathway is mainly involved in cell proliferation and differentiation, while JNK and p38 pathways are mainly involved in cell stress response and apoptosis [87]. Meanwhile, JNK and p38 have high phosphorylation levels in tumor resistant cells [88]. Zhao and co-workers found proanthocyanidins inhibited the phosphorylation of JNK and p38 in A2780/T cells. Furthermore, proanthocyanidins effectively inhibited P-gp expression by blocking MDR1 gene transcription and increasing the intracellular accumulation of P-gp substrate rhodamine-123 [69]. Consistent with this result, quercetin reversed P-gp associated MDR by inhibiting the expression and function of $\mathrm{P}$-gp through downregulation of NF- $\kappa \mathrm{B}$ activity and MAPK/ERK pathway as mediated YB-1 nuclear translocation (Chen et al.), offering an insight into the reversing mechanism of MDR by flavonoids. When cells are stimulated by anticancer drugs, YB-1 can translocate from cytoplasm to nucleus, specifically bind to the Y-box regulatory element of MDR1 gene promoter, inducing the expression of MDR1 gene [89]. In addition, the down-regulation in MDR1 mRNA and P-gp expression through MAPK/ERK pathway in MCF-7/ADR and K562/ADR could be also induced by different concentrations of dihydromyricetin $(1,5,10 \mu \mathrm{M})$ [90]. (author?) [91] investigated the correlation between flavonoid paeonol and K562/doxorubicin drug-resistant cell line. They found the paeonol was effective in enhancing the concentration of intracellular drug. When doxorubicin was combined with paeonol, the reversal multiple was more than 20 times, and the expression of P-gp drugresistant gene was significantly down regulated. The expression of p38 kinase in MAPK signaling pathway was also significantly decreased in drug-resistant cells treated with paeonol [68]. In exploring the effect of signal pathway on apoptosis rate, the results showed that p-ERK was significantly decreased after being treated with flavone and doxorubicin combination [92]. When cancer cells were exposed to chemotherapy drugs for a long time, P-gp mRNA dependence got increased. In terms of MAPK pathway, flavonoids may activate nuclear metastasis of YB-1 and reduce P-gp expression by inhibiting ERK1/2 phosphorylation [71]. In addition, p38 MAPK and Akt/MAPK in MAPK signaling pathway were upstream regulatory enzymes of NF- $\kappa$ B pathway, which could promote the phosphorylation of NF- $\kappa \mathrm{B}$ and participate in the regulation of P-gp expression [93]. Flavonoids were also able to inhibit the expression of P-gp by inhibiting the phosphorylation of p38 [36]. 
Table 2 Overview of literature on the effect of dietary flavonoids with MDR reversal effects and their application.

\begin{tabular}{|c|c|c|c|}
\hline Flavonoids & Model system & Functions & Reference \\
\hline Genistein & $\begin{array}{l}\text { Rat, MCF-7, PC3 prostate cancer } \\
\text { cells }\end{array}$ & $\begin{array}{l}\mathrm{ABC} \text { transporters regulation, ROS induction, } \\
\mathrm{NF}-\kappa \mathrm{B} \text { inhibition, modulates } \mathrm{P}-\mathrm{gp} \text { expression }\end{array}$ & {$[38,78]$} \\
\hline Nobiletin, & Mouse macrophages J774.1 & $\mathrm{ABC}$ transporters regulation, activates $\mathrm{AMPK}$ & [39] \\
\hline Tangeretin & Caco-2 cells & $\begin{array}{l}\text { ABC transporters regulation, stimulates } \\
\text { the ATPase activity }\end{array}$ & {$[40]$} \\
\hline $\begin{array}{l}\text { Catechin-gallate, } \\
\text { epigallocatechin-gallate, } \\
\text { epicatechin-gallate }\end{array}$ & KB-C2 cells and Caco- 2 cells & Inhibits the efflux of P-gp substrates & {$[79,80]$} \\
\hline Quercetin & EPG85-257RDB cells & $\begin{array}{l}\text { Decreases of P-gp expression, inhibit drug } \\
\text { transport, down-regulates of ABCB1 gene } \\
\text { expression }\end{array}$ & {$[81]$} \\
\hline Apigenin, naringenin & Caco-2 cells & $\begin{array}{l}\text { Downregulates ABC transporter, inhibits P-gp } \\
\text { activity and ATPase }\end{array}$ & {$[41]$} \\
\hline Kaempferol, & KB-3-1 cells (lacking Pgp) & $\begin{array}{l}\text { Decreases of P-gp expression, inhibits P-gp } \\
\text { activity }\end{array}$ & {$[82,83]$} \\
\hline Naringin & Sprague Dawley rats & $\begin{array}{l}\text { ABC transporters regulation, inhibits the } \\
\text { doxorubicin-stimulated ATPase activity, } \\
\text { induction of GSH and GST, NF- } \kappa \text { B inhibition, } \\
\text { modulates P-gp expression }\end{array}$ & {$[42]$} \\
\hline Acacetin & NSCLC cells & Downregulates MDR1 transporter & {$[43]$} \\
\hline Chrysin & $\begin{array}{l}\text { ABC-transfected cells, } \\
\text { MDA-MB-231 cells }\end{array}$ & $\begin{array}{l}\text { Sensitizes mitoxantrone, inhibit } \mathrm{ABCB} 1 \\
\text { mediated rhodamine } 123, \mathrm{ABC} \text { transporters } \\
\text { regulation }\end{array}$ & [44-46] \\
\hline Diosmetin, erythromycin & Staphylococcus aureus & Inhibit the growth of ABC-pump & [84] \\
\hline Naringenin & Caco-2 cells & $\mathrm{ABC}$ transporters regulation & {$[47]$} \\
\hline Daidzein, genistein & MCF-7, MDA-MB-231 cells & $\begin{array}{l}\text { Inhibition of BCRP activity and sensitization to } \\
\text { BCRP substrates }\end{array}$ & [85] \\
\hline Biochanin A, phloretin & MCF-7, MDA435/LCC6 & $\begin{array}{l}\text { Stimulates P-gp ATPase activity, inhibits } \\
\text { P-gp-mediated cellular efflux }\end{array}$ & {$[49,50]$} \\
\hline Morin, silymarin & MCF-7, MDA435/LCC6 & $\begin{array}{l}\text { Inhibits P-gp ATPase activity, inhibits } \\
\text { P-gp-mediated cellular efflux }\end{array}$ & {$[50]$} \\
\hline
\end{tabular}

\subsection{COX-2 signaling pathway}

COX-2 is the source of reactive oxygen species (ROS). Excessive COX-2 can significantly increase the ROS level in cells, inducing oxidative stress. The concentration of ROS in tumor cells is significantly higher than that in normal cells [94]. When a high concentration of ROS poses a threat to cells' survival, the expression and clearance capacity of P-gp will increase in a stress manner to prevent our body from absorbing harmful substances and from being damaged by peroxidation [95]. Xiao and Coauthros (author?) [96] treated HL-60 and HL-60a resistant strains with quercetin for $48 \mathrm{~h}$, and found that quercetin could induce apoptosis of both strains, and the apoptosis rate increased with the increase of quercetin concentration. The apoptosis rates of HL-60 and HL-60a cells, as well as the expression of COX-2 protein, were all correlated to P-gp mRNA and COX-2 mRNA [96], suggesting that flavonoids might induce apoptosis by inhibiting the expressions of COX-2 and P-gp and initiating caspase-3 cascade ( ; Breier et al., 2012) [97]. A further study showed that $10 \mu \mathrm{M}$ apigenin combined with doxorubicin could reverse the IC50 value of ADM cells by 3.04 times and significantly increase the growth inhibition rate of bel7401/ADM cells [98]. After apigenin treatment, the expression level of $\mathrm{p}$-Akt was significantly down regulated $(\mathrm{P}<0.01)$, suggesting that reversing effect of apigenin on drug resistance may be associated with inhibiting the expression of p-Akt [98]. Inhibition of Akt

can improve the drug resistance of cells. COX-2 and PI3K/Akt pathway belong to the upstream and downstream relationship, and glycogen synthase kinase $3 \beta$ (GSK-3 $\beta$ ) is the downstream protein of Akt [99]. Therefore, flavonoids may inhibit the expression of COX- 2 and the phosphorylation of GSK- $3 \beta / \beta$-Catenin to regulate the expression of downstream P-gp transcription factors. Another possible mechanism is the transcriptional activity that depends on the expressions of COX-2 and P-gp [100, 101].

\subsection{GST- $\pi$ pathway}

GST is a class of enzymes that catalyze the binding of glutathione (GSH) with electrophilic substances in the body. Among their five subtypes, GST- $\pi$ is closely related to tumor and has GSH binding site. Anticancer drugs can induce the increase of GST- $\pi$ expression, catalyze the combination of GSH with chemotherapeutic drugs and be excreted out of cells, leading to the drug resistance [102]. Another study reported by Balyan and co-authors investigated the effect of luteolin on GST- $\pi$ of K562/A02 drug-resistant cell line and found luteolin significantly reduced the GSH content in K562/A02 cells, and the expression of GST- $\pi$ protein was decreased by $22 \%, 26 \%$ and $34 \%$ on day 1,3 and 5 , respectively [103]. It was speculated that the mechanism for some flavonoids to reverse drug resistance may be related to GST- $\pi$, mainly by inhibiting the 
combination of anticancer drugs with GSH [104]. However, studies also supported that kaempferol [105] and hesperetin [106] could change the expressions of GST- $\pi$ and P-gp in drug-resistant strains, and the mechanism of reversing MDR characteristics might be due to the inhibition in the change of P-gp expression induced by GST$\pi$. Moreover, after quercetin treatment, the reversed multiple of $\mathrm{Bel} / \mathrm{Fu}$ resistant strain could reach 2.4 times, and the expression of GST- $\pi$ gene in cells could be significantly down regulated, and meanwhile, the ratio of $\mathrm{P}-\mathrm{gp} / \beta$-Catenin was decreased [36]. Xu and Co-authors (author?) [107] discussed the effect of Baicalin on the MDR characteristics of lung cancer cells A549 and its mechanism. The results indicated that the growth of lung cancer cells treated with baicalin was significantly inhibited in time and concentration dependent manners; the expression of MDR1 and GST- $\pi$ mRNA in tumor cells treated with baicalin was significantly decreased [107]. When apigenin was combined with doxorubicin, the combination reduced the content of GST- $\pi$ to $18 \%$ and the level of ROS increased by more than $20 \%$ compared to doxorubicin treatment [108]. GST- $\pi$, as an enzyme related to detoxification, is involved in the detoxification process of free radicals produced by oxidants and cytotoxic substances [109]. In this line, flavonoids may also inhibit the expression of GST- $\pi$ by inhibiting the entry of nuclear factor E2 related factor 2 (Nrf2) into the nucleus and binding with the promoter of downstream target gene GST- $\pi$, thereby increasing the level of ROS involved in the tyrosine kinase signaling pathway as a second messenger and regulating the expression of P-gp [110].

\section{DISPOSITION OF FLAVONOIDS IMPACTS THEIR EFFECT ON ABC TRANSPORTER}

The disposition of flavonoids in the gastrointestinal tract after dietary digestion provided numerous promises for human health.

Correspondingly, the ability of flavonoids to shape the gastrointestinal tract offers the prospective of diet based therapies for a wide array of conditions associated with dysbiosis [111]. Actually, the flavonoids after ingestion will undergo a metabolic pathways in the small intestine to produce glycosides [11]. An enormous amount of the administrated flavonoids will be transported and converted into phenolic acids in the colon by microflora. Further transportation and metabolism through the hepatic portal vein often happened in the liver. As shown in Figure 6, phase I and phase II metabolism of flavonoids resulted in more polar compoundgeneration. The metabolites then reach the targeted tissues or are excreted by the kidneys. Many factors such as low solubility, high degradation rate, and low metabolism limit the bioavailability of flavonoids. Phase II enzymes such as uridine- $5^{\prime}$-diphosphate glucuronosyltransferases (UGTs) and catechol-O- methyl transferases (COMT) are involved in extensive first pass metabolism of flavonoids by transforming them to more hydrophilic forms for excretion (Fernandes et al., 2016) [112]. As followed, the effluxes of flavonoids getting out of intestinal cells return to the lumen for excretion as modulated by $\mathrm{ABC}$ transporters, which also limits their bioavailability [113]. In another word, depending on their structure, flavonoids and their metabolites might act as inducers or inhibitors of ABC transporters and phase II metabolizing enzymes [114].

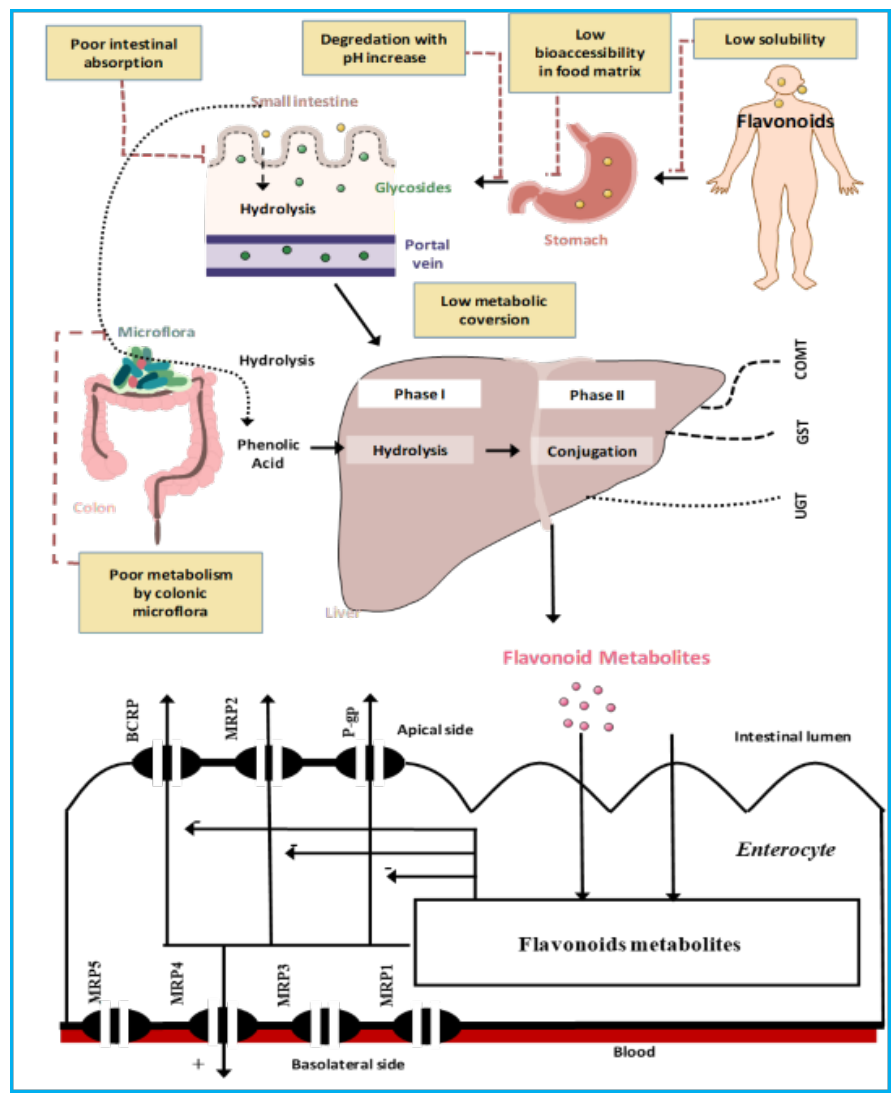

Figure 6 Schematic representation of metabolism andfactors limiting the bioavailability of flavonoids. Abbreviations: UGT,UDPglucuronosyltransferase; GST, glutathione S-transferase; COMT, catecholO-methyltransferase.

\section{CONCLUSIONS}

Researchers have shown the therapeutic effect of flavonoids in a variety of diseases, but its low bioavailability significantly limits its clinical application, which is closely related to intestinal absorption and metabolism. The absorption and metabolism mediated by intestinal phase II drug metabolizing enzymes (UGTs and SLUTs) and efflux transporters (P-gp, BCRP and MRPs) have attracted extensive attention and became a hot topic on the pharmacokinetics of flavonoids. Once being absorbed by intestinal epithelial cells, flavonoids would be widely used by phase II enzymes; meanwhile, drug metabolizing enzymes are coupled with efflux transporters to prevent their absorption. Therefore, the coupling of intestinal drug metabolizing enzymes with efflux transporters is considered as the main reason for the low bioavailability of flavonoids (e.g., genistein, daidzein, Robinia pseudoacacia, quercetin, kaempferol, chrysin and apigenin). it also forms hydrophilic metabolites (glucuronide/sulfate) catalyzed by phase II drug metabolizing enzymes UGTs and SLUTs, which cannot penetrate cell membrane by passive diffusion. The binding metabolites of these flavonoids are the substrates of BCRP and MRP2. The external transporters can regulate the rate of the extracellular glucuronide/sulfate, and then affect the formation of glucuronide/ sulfation, increasing the retention time of flavonoid compounds and glucuronides in the local intestine. 
Table 3 nteractions between transporters and flavonoids. Adapt from Jiang and $\mathrm{Hu}, 2012$

\begin{tabular}{|c|c|c|c|}
\hline Transporters & Substrates & Flavonoids as modulators & Inhibitor \\
\hline P-gp & Flavonoid aglycone & $\begin{array}{l}\text { Catechin,epicatechin, grapefruit } \\
\text { juice, Quercetin and kaempherol }\end{array}$ & $\begin{array}{l}\text { EGCG, quercetin Kaempherol, chrysin, flavones, } \\
\text { hesperetin,naringenin, genistein }\end{array}$ \\
\hline MRPs & $\begin{array}{l}\text { Flavonoid glucuronides } \\
\text { and sulfates }\end{array}$ & Chrysin & $\begin{array}{l}\text { Genistein, kaempferol, Flavopiridol, chrysin, } \\
\text { quercetin, biochanin A, catechin, EGCG, } \\
\text { quercetin-7-O-glucuronide }\end{array}$ \\
\hline BCRP coumestrin & $\begin{array}{l}\text { Flavonoid glucuronides } \\
\text { and sulfates }\end{array}$ & Quercetin,chrysin and flavone & $\begin{array}{l}\text { chrysin, biochanin A, apigenin, genistein, fisetin, } \\
\text { kaempferol, hesperetin, naringenin, quercetin, } \\
\text { luteolin-4-glucoside, daidzein-7-glucuronide, } \\
\text { daidzein-4-sulfate, daidzin,ononin, genistein, } \\
\text { sissotrin, glycitin }\end{array}$ \\
\hline
\end{tabular}

On the contrary, the inhibition of intestinal efflux transporters can increase drug absorption and reduce drug metabolism, thus significantly increasing drug bioavailability. Efflux transporters act as a "revolving gate" to regulate the in vivo bioavailability of flavonoids ((Table 3)). Therefore, the study of flavonoid in vivo treatment should not only consider the influence of a single drug metabolic enzyme or transporter, but also consider the coupling effect of enzyme-external transport on drug metabolism. At the same time, metabolic enzyme and efflux transporter coupling will further affect the drug interaction, clinical efficacy, and toxicity of flavonoids. At present, the main challenge to study the coupling of phase II drug metabolism (glucuronization/sulfation)-external transport coupling is the lack of specific transporter inhibitors. In recent years, many research groups have successfully constructed a variety of coupling models for metabolic enzyme transporter by using small interfering RNA (siRNA) or short hairpin RNA (shRNA) technology to silence metabolic enzyme and transporter genes. In conclusion, metabolic enzyme transporter coupling plays a crucial role in the treatment of flavonoids and drug interaction, which will significantly change the clinical efficacy and toxicity of the drug.

\section{CONFLICTS OF INTEREST}

The authors declare no competing financial interest.

\section{ACKNOWLEDGEMENTS}

This work is supported by the National Natural Science Foundation of China (NSFC, Grant No. 32072209, Grant No. 31801459); China Postdoctoral Science Foundation Funded Project (2020M682073); Science and Technology General Projects of Fujian Province (2019J01393).

\section{REFERENCES}

[1] Chen L, Teng H, Jia Z, Battino M, Miron A, Yu Z. Intracellular signaling pathways of inflammation modulated by dietary flavonoids: The most recent evidence. . Critical Reviews in Food Science and Nutrition. 2018;58:2908-2924.

[2] Cassidy A, Minihane AM. The role of metabolism (and the microbiome) in defining the clinical efficacy of dietary flavonoids. The American journal of clinical nutrition. 2017;105(1):10-22.

[3] Pathania S, Bhatia R, Baldi A, Singh R, Rawal RK. Drug metabolizing enzymes and their inhibitors' role in cancer resistance. Biomedicine \& Pharmacotherapy. 2018;105:53-65.

[4] Docampo M, Olubu A, Wang X, Pasinetti G, Dixon RA. Glucuronidated flavonoids in neurological protection: Structural analysis and approaches for chemical and biological synthesis. Journal of agricultural and food chemistry. 2017;65(35):76077623.

[5] Chambers CS, Viktorová J, Řehořová K, Biedermann D, Turková L, Macek T, et al. Defying multidrug resistance! Modulation of related transporters by flavonoids and flavonolignans. Journal of agricultural and food chemistry. 2019;68(7):1763-1779.

[6] Kiani YS, Jabeen I. Exploring the chemical space of cytochrome p450 inhibitors using integrated physicochemical parameters, drug efficiency metrics and decision tree models. Computation. 2019;7(2):26-26.

[7] Allam RM, El-Halawany AM, Al-Abd AM. Chemosensitizing agents from natural origin for colorectal cancer: Pharmacodynamic and cellular pharmacokinetics approaches. Drug Resistance in Colorectal Cancer: Molecular Mechanisms and Therapeutic Strategies. 2020;p. 93-116.

[8] Akamine Y, Yasui-Furukori N, Uno T. Drug-drug interactions of P-gp substrates unrelated to CYP metabolism. Current drug metabolism. 2019;20(2):124-129.

[9] Elmeliegy M, Vourvahis M, Guo C, Wang DD. Effect of Pglycoprotein (P-gp) inducers on exposure of P-gp substrates: Review of clinical drug-drug interaction studies. Clinical pharmacokinetics. 2020;59(6):699-714.

[10] Sun X, Tang S, Hou B, Duan Z, Liu Z, Li Y, et al. Overexpression of P-glycoprotein, MRP2, and CYP3A4 impairs intestinal absorption of octreotide in rats with portal hypertension. BMC gastroenterology. 2021;21(1):1-15.

[11] Teng H, Chen L. 2019.

[12] Sampson KE, Brinker A, Pratt J, Venkatraman N, Xiao Y, Blasberg $\mathrm{J}$, et al. Zinc finger nuclease-mediated gene knockout results in loss of transport activity for P-glycoprotein, BCRP, and MRP2 in Caco-2 cells. Drug Metabolism and Disposition. 2015;43(2):199207.

[13] Takano M, Yumoto R, Murakami T. Expression and function of efflux drug transporters in the intestine. Pharmacology \& therapeutics. 2006;109(1-2):137-161.

[14] Leslie EM, Deeley RG, Cole SP. Toxicological relevance of the multidrug resistance protein 1, MRP1 (ABCC1) and related transporters. Toxicology. 2001;167(1):3-23.

[15] Hitchcock SA. Structural modifications that alter the Pglycoprotein efflux properties of compounds. Journal of Medicinal Chemistry. 2012;55(11):4877-4895.

[16] Williamson G, Kay CD, Crozier A. The bioavailability, transport, and bioactivity of dietary flavonoids: A review from a historical perspective. Comprehensive Reviews in Food Science and Food 
Safety. 2018;17(5):1054-1112.

[17] Fernandes I, Faria A, Calhau C, Freitas VD, Mateus N. Bioavailability of anthocyanins and derivatives. Journal of functional foods. 2014;7:54-66.

[18] Fernandes SS, Coelho MS, Las MD, Salas-Mellado M. Bioactive compounds as ingredients of functional foods: polyphenols, carotenoids, peptides from animal and plant sources new. Bioactive Compounds: Health Benefits and Potential Applications. 2019;p. 129-142.

[19] Haslam IS, Jones K, Coleman T, Simmons NL. Induction of P-glycoprotein expression and function in human intestinal epithelial cells (T84). Biochemical Pharmacology. 2008;76(7):850-861.

[20] Zubiaur P, Saiz-Rodríguez M, Koller D, Ovejero-Benito MC, Wojnicz A, Abad-Santos F. How to make P-glycoprotein (ABCB1, MDR1) harbor mutations and measure its expression and activity in cell cultures. Pharmacogenomics. 2018;19(16):1285-1297.

[21] Nicklisch SC, Hamdoun A. Disruption of small molecule transporter systems by Transporter-Interfering Chemicals (TICs). FEBS letters. 2020;594(23):4158-4185.

[22] Marchetti S, Mazzanti R, Beijnen JH, Schellens JH. Concise review: clinical relevance of drug-drug and herb-drug interactions mediated by the ABC transporter ABCB1 (MDR1, P-glycoprotein). The oncologist. 2007;12(8):927-941.

[23] Sun J, He ZG, Cheng G, Wang SJ, Hao XH, Zou MJ. Multidrug resistance P-glycoprotein: crucial significance in drug disposition and interaction. Medical Science Monitor. 2004;10(1):5-14.

[24] Hou YC, Lin SP, Chao PDL. Liquorice reduced cyclosporine bioavailability by activating P-glycoprotein and CYP 3A. Food chemistry. 2012;135(4):2307-2312.

[25] Tachibana T, Kitamura S, Kato M, Mitsui T, Shirasaka Y, Yamashita S, et al. Model analysis of the concentrationdependent permeability of P-gp substrates. Pharmaceutical research. 2010;27(3):442-446.

[26] Muzi M, Mankoff DA, Link JM, Shoner S, Collier AC, Sasongko $\mathrm{L}$, et al. Imaging of cyclosporine inhibition of P-glycoprotein activity using $11 \mathrm{C}$-verapamil in the brain: studies of healthy humans. Journal of Nuclear Medicine. 2009;50(8):1267-1275.

[27] Shaik N, Pan G, Elmquist WF. Interactions of pluronic block copolymers on P-gp efflux activity: Experience with HIV1 protease inhibitors. Journal of pharmaceutical sciences. 2008;97(12):5421-5433.

[28] Merino G, Alvarez AI, Pulido MM, Molina AJ, Schinkel AH, Prieto JG. Breast cancer resistance protein (BCRP/ABCG2) transports fluoroquinolone antibiotics and affects their oral availability, pharmacokinetics, and milk secretion. Drug Metabolism and Disposition. 2006;34(4):690-695.

[29] Li S, Zhang W, Yin X, Xing S, Xie HQ, Cao Z, et al. Mouse ATP-binding cassette $(\mathrm{ABC})$ transporters conferring multidrug resistance. Anti-Cancer Agents in Medicinal Chemistry. 2015;15(4):423-432.

[30] Rowbottom C, Pietrasiewics A, Tuczewycz T, Grater R, Qiu D, Kapadnis S, et al. Optimization of dose and route of administration of the P-glycoprotein inhibitor, valspodar (PSC833 ) and the P-glycoprotein and breast cancer resistance protein dual-inhibitor, elacridar (GF120918) as dual infusion in rats. Pharmacology research \& perspectives. 2021;9(2):740-740.

[31] Durmus S, Valk MVD, Teunissen SF, Song JY, Wagenaar E, Beijnen JH, et al. ABC transporters Mdr1a/1b, Bcrp1, Mrp2 and Mrp3 determine the sensitivity to PhIP/DSS-induced colon carcinogenesis and inflammation. Archives of toxicology.
2019;93(3):775-790.

[32] Nigam SK, Wu W, Bush KT, Hoenig MP, Blantz RC, Bhatnagar V. Handling of drugs, metabolites, and uremic toxins by kidney proximal tubule drug transporters. Clinical journal of the American Society of Nephrology. 2015;10(11):2039-2049.

[33] Willenberg I, Elsner LV, Steinberg P, Schebb NH. Development of an online-SPE-LC-MS method for the investigation of the intestinal absorption of 2-amino-1-methyl-6-phenylimidazo [4, 5-b] pyridine (PHIP) and its bacterial metabolite PHIP-M1 in a Caco-2 Transwell system. Food chemistry. 2015;166:537-543.

[34] Vlaming ML, Teunissen SF, Steeg EVD, Esch AV, Wagenaar E, Brunsveld L, et al. Bcrp1; Mdr1a/b; Mrp2 combination knockout mice: altered disposition of the dietary carcinogen PhIP (2-amino-1-methyl-6-phenylimidazo [4, 5-b] pyridine) and its genotoxic metabolites. Molecular pharmacology. 2014;85(3):520-530.

[35] Dietrich CG, Waart DRD, Ottenhoff R, Bootsma AH, Gennip AHV, Elferink RPO. Mrp2-deficiency in the rat impairs biliary and intestinal excretion and influences metabolism and disposition of the food-derived carcinogen 2-amino-1-methyl6-phenylimidazo [4, 5-b] pyridine (PhIP). Carcinogenesis. 2001;22(5):805-811.

[36] Wang P, Yang HL, Yang YJ, Wang L, Lee SC. 2015.

[37] Sesink AL, Arts IC, Boer VCD, Breedveld P, Schellens $\mathrm{JH}$, Hollman PC, et al. Breast cancer resistance protein (Bcrp1/Abcg2) limits net intestinal uptake of quercetin in rats by facilitating apical efflux of glucuronides. Molecular pharmacology. 2005;67(6):1999-2006.

[38] Semeniuk M, Ceré LI, Ciriaci N, Bucci-Muñoz M, Villanueva SSM, Mottino AD. Regulation of hepatic P-gp expression and activity by genistein in rats. Archives of toxicology. 2020;p. 1-11.

[39] Tsuboi T, Lu R, Yonezawa T, Watanabe A, Woo JT, AbeDohmae S, et al. Molecular mechanism for nobiletin to enhance ABCA1/G1 expression in mouse macrophages. Atherosclerosis. 2020;297:32-39.

[40] Feng SL, Yuan ZW, Yao XJ, Ma WZ, Liu L, Liu ZQ, et al. Tangeretin, a citrus pentamethoxyflavone, antagonizes $\mathrm{ABCB} 1$-mediated multidrug resistance by inhibiting its transport function. Pharmacological research. 2016;110:193-204.

[41] Ravisankar S, Agah S, Kim H, Talcott S, Wu C, Awika J. Combined cereal and pulse flavonoids show enhanced bioavailability by downregulating phase II metabolism and ABC membrane transporter function in Caco-2 model. Food chemistry. 2019;279:88-97.

[42] Ali MM, Agha FG, El-Sammad NM, Hassan SK. Modulation of anticancer drug-induced P-glycoprotein expression by naringin. Zeitschrift für Naturforschung C. 2009;64(1-2):109-116.

[43] Punia R, Raina K, Agarwal R, Singh RP. Acacetin enhances the therapeutic efficacy of doxorubicin in non-small-cell lung carcinoma cells. Plos One. 2017;12(8):182870-182870.

[44] Molnar J, Engi H, Hohmann J, Molnar P, Deli J, Wesolowska O. Reversal of multidrug resitance by natural substances from plants. Current Topics Medicinal Chemistry. 2010;10:17571768.

[45] Wang X, Morris ME. Effects of the flavonoid chrysin on nitrofurantoin pharmacokinetics in rats: potential involvement of ABCG2. Drug Metab Dispos. 2007;35:268-74.

[46] Ahmed-Belkacem A, Pozza A, Munoz-Martinez F, Bates SE, Castanys S, Gamarro F. Flavonoid structure-activity studies identify 6-prenylchrysin and tectochrysin as potent and specific inhibitors of breast cancer resistance protein ABCG2. Cancer Research. 2005;65:4852-4860. 
[47] Chabane MN, Ahmad AA, Peluso J, Muller CD, Séquier G. Quercetin and naringenin transport across human intestinal Caco-2 cells. Journal of Pharmacy and Pharmacology. 2009;(11):1473-1483.

[48] Navarro-Hortal MD, Varela-López A, Romero-Márquez JM, Rivas-García L, Speranza L, Battino M, et al. Role of flavonoids against adriamycin toxicity. Food and Chemical Toxicology. 2020;

[49] Chung SY, Sung MK, Kim NH, Jang JO, Go EJ, Lee HJ. Inhibition of P-glycoprotein by natural products in human breast cancer cells. Archives of pharmacal research. 2005;28(7):823-828.

[50] Zhang S, Morris ME. Effects of the flavonoids biochanin A, morin, phloretin, and silymarin on P-glycoprotein-mediated transport. Journal of Pharmacology and Experimental Therapeutics. 2003;304(3):1258-1267.

[51] Bansal T, Jaggi M, Khar R, Talegaonkar S. Emerging significance of flavonoids as P-glycoprotein inhibitors in cancer chemotherapy. Journal of pharmacy \& pharmaceutical sciences. 2009;12(1):46-78.

[52] Matsson P, Pedersen JM, Norinder U, Bergström CA, Artursson P. Identification of novel specific and general inhibitors of the three major human ATP-binding cassette transporters Pgp, BCRP and MRP2 among registered drugs. Pharmaceutical research. 2009;26(8):1816-1831.

[53] Jin H, Zhu Y, Wang C, Meng Q, Wu J, Sun P, et al. Molecular pharmacokinetic mechanism of the drug-drug interaction between genistein and repaglinide mediated by P-gp. Biomedicine \& Pharmacotherapy. 2020;125:110032-110032.

[54] Rigalli JP, Ciriaci N, Arias A, Ceballos MP, Villanueva SSM, Luquita MG, et al. Regulation of multidrug resistance proteins by genistein in a hepatocarcinoma cell line: impact on sorafenib cytotoxicity. Plos one. 2015;10(3):119502-119502.

[55] Zhang S, Sagawa K, Arnold RD, Tseng E, Wang X, Morris ME. Interactions between the flavonoid biochanin A and Pglycoprotein substrates in rats: in vitro and in vivo. Journal of pharmaceutical sciences. 2010;99(1):430-441.

[56] Ma W, Feng S, Yao X, Yuan Z, Liu L, Xie Y. Nobiletin enhances the efficacy of chemotherapeutic agents in ABCB1 overexpression cancer cells. Scientific reports. 2015;5(1):1-15.

[57] Coley HM. Overcoming multidrug resistance in cancer: clinical studies of p-glycoprotein inhibitors. Multi-drug resistance in cancer. 2010;p. 341-358.

[58] Ferreira A, Rodrigues M, Fortuna A, Falcão A, Alves G. Flavonoid compounds as reversing agents of the P-glycoproteinmediated multidrug resistance: An in vitro evaluation with focus on antiepileptic drugs. Food Research International. 2018;103:110-120.

[59] Wen C, Fu L, Huang J, Dai Y, Wang B, Xu G, et al. Curcumin reverses doxorubicin resistance via inhibition the efflux function of ABCB4 in doxorubicin\&\#8209; resistant breast cancer cells. Molecular medicine reports. 2019;19(6):5162-5168.

[60] Choi JS, Piao YJ, Kang KW. Effects of quercetin on the bioavailability of doxorubicin in rats: role of CYP3A4 and Pgp inhibition by quercetin. Archives of pharmacal research. 2011;34(4):607-613.

[61] Szafraniec MJ, Szczygieł M, Urbanska K, Fiedor L. Determinants of the activity and substrate recognition of breast cancer resistance protein (ABCG2). Drug metabolism reviews. 2014;46(4):459-474.

[62] Ikegawa T, Ushigome F, Koyabu N, Morimoto S, Shoyama Y, Naito M, et al. 2000.

[63] Okura T, Ibe M, Umegaki K, Shinozuka K, Yamada S. Effects of dietary ingredients on function and expression of P- glycoprotein in human intestinal epithelial cells. Biological and Pharmaceutical Bulletin. 2010;33(2):255-259.

[64] Nguyen H, Zhang S, Morris ME. Effect of flavonoids on MRP1mediated transport in Panc-1 cells. Journal of pharmaceutical sciences. 2003;92(2):250-257.

[65] Wang Q, Morris ME. Flavonoids modulate monocarboxylate transporter-1-mediated transport of $\gamma$-hydroxybutyrate in vitro and in vivo. Drug Metabolism and Disposition. 2007;35:201-208.

[66] Conseil G, Baubichon-Cortay H, Dayan G, Jault JM, Barron D, Pietro AD. Flavonoids: a class of modulators with bifunctional interactions at vicinal ATP-and steroid-binding sites on mouse Pglycoprotein. Proceedings of the National Academy of Sciences. 1998;95(17):9831-9836.

[67] Schutte ME, Sandt JJVD, Alink GM, Groten JP, Rietjens IM. Myricetin stimulates the absorption of the pro-carcinogen PhIP. Cancer letters. 2006;231(1):36-42.

[68] Ramachandhiran D, Vinothkumar V, Babukumar S. Paeonol exhibits anti-tumor effects by apoptotic and anti-inflammatory activities in 7, 12-dimethylbenz (a) anthracene induced oral carcinogenesis. Biotechnic \& Histochemistry. 2019;94(1):10-25.

[69] Zhao BX, Sun YB, Wang SQ, Duan L, Huo QL, Ren F, et al. Grape seed procyanidin reversal of p-glycoprotein associated multi-drug resistance via down-regulation of NF- $\kappa \mathrm{B}$ and MAPK/ERK mediated YB-1 activity in A2780/T cells. Plos one. 2013;8(8):71071-71071.

[70] Kim DH, Hossain MA, Kang YJ, Jang JY, Lee YJ, Im E. Baicalein, an active component of Scutellaria baicalensis Georgi, induces apoptosis in human colon cancer cells and prevents AOM/DSSinduced colon cancer in mice. International journal of oncology. 2013;43(5):1652-1658.

[71] Zhu H, Liu Z, Tang L, Liu J, Zhou M, Xie F. Reversal of P-gp and MRP1-mediated multidrug resistance by $\mathrm{H} 6$, a gypenoside aglycon from Gynostemma pentaphyllum, in vincristineresistant human oral cancer (KB/VCR) cells. European journal of pharmacology. 2012;696(1-3):43-53.

[72] Kaur D, Deshmukh R. 2021.

[73] Begum D, Merchant N, Nagaraju GP. Role of Specific Phytochemicals Against Gastrointestinal Malignancies. In: Phytochemicals Targeting Tumor Microenvironment in Gastrointestinal Cancers. Springer; 2020. p. 1-33.

[74] Huang CZ, Wang YF, Zhang Y, Peng YM, Liu YX, Ma F, et al. Cepharanthine hydrochloride reverses P\&\#8209; glycoproteinmediated multidrug resistance in human ovarian carcinoma A2780/Taxol cells by inhibiting the PI3K/Akt signaling pathway. Oncology reports. 2017;38(4):2558-2564.

[75] Palko-Labuz A, Sroda-Pomianek K, Uryga A, Kostrzewa-Suslow E, Michalak K. Anticancer activity of baicalein and luteolin studied in colorectal adenocarcinoma LoVo cells and in drugresistant LoVo/Dx cells. Biomedicine \& Pharmacotherapy. 2017;88:232-241.

[76] Chao JI, Su WC, Liu HF. Baicalein induces cancer cell death and proliferation retardation by the inhibition of CDC2 kinase and survivin associated with opposite role of p38 mitogen-activated protein kinase and AKT. Molecular cancer therapeutics. 2007;6(11):3039-3048.

[77] Xia Y, Choi HK, Lee K. Recent advances in hypoxia-inducible factor (HIF)-1 inhibitors. European journal of medicinal chemistry. 2012;49:24-40.

[78] Rigalli JP, Tocchetti GN, Arana MR, Villanueva SSM, Catania VA, Theile D, et al. The phytoestrogen genistein enhances multidrug resistance in breast cancer cell lines by translational regulation of ABC transporters. Cancer letters. 2016;376(1):165-172. 
[79] Kitagawa S, Nabekura T, Kamiyama S. Inhibition of Pglycoprotein function by tea catechins in KB-C2 cells. Journal of pharmacy and pharmacology. 2004;56(8):1001-1005.

[80] Jodoin J, Demeule M, Béliveau R. Inhibition of the multidrug resistance P-glycoprotein activity by green tea polyphenols. Biochimica et Biophysica Acta (BBA)-Molecular Cell Research. 2002;1542(1-3):149-159.

[81] Borska S, Chmielewska M, Wysocka T, Drag-Zalesinska M, Zabel M, Dziegiel P. In vitro effect of quercetin on human gastric carcinoma: targeting cancer cells death and MDR. Food and chemical toxicology. 2012;50(9):3375-3383.

[82] Limtrakul P, Khantamat O, Pintha K. Inhibition of P-glycoprotein function and expression by kaempferol and quercetin. Journal of chemotherapy. 2005;17(1):86-95.

[83] Zhu H, Gao J, Wang L, Qian KJ, Cai LP. 2018.

[84] Chan BC, Ip M, Gong $H$, Lui SL, See RH, Jolivalt C. Synergistic effects of diosmetin with erythromycin against ABC transporter over-expressed methicillin-resistant Staphylococcus aureus (MRSA) RN4220/pUL5054 and inhibition of MRSA pyruvate kinase. Phytomedicine. 2013;20(7):611-614.

[85] Rigalli JP, Scholz PN, Tocchetti GN, Ruiz ML, Weiss J. The phytoestrogens daidzein and equol inhibit the drug transporter BCRP/ABCG2 in breast cancer cells: Potential chemosensitizing effect. European journal of nutrition. 2019;58(1):139-150.

[86] Zhang W, Liu HT. MAPK signal pathways in the regulation of cell proliferation in mammalian cells. Cell research. 2002;12(1):9-18.

[87] Junttila MR, Li SP, Westermarck J. Phosphatase-mediated crosstalk between MAPK signaling pathways in the regulation of cell survival. FASEB Journal. 2008;22(4):954-965.

[88] Zhang X, Wang X, Wu T, Li B, Liu T, Wang R, et al. Isoliensinine induces apoptosis in triple-negative human breast cancer cells through ROS generation and p38 MAPK/JNK activation. Scientific reports. 2015;5(1):1-13.

[89] Kosnopfel C, Sinnberg T, Schittek B. Y-box binding protein 1a prognostic marker and target in tumour therapy. European journal of cell biology. 2014;93(1-2):61-70.

[90] Sun Y, Wang C, Meng Q, Liu Z, Huo X, Sun P, et al. Targeting Pglycoprotein and SORCIN: Dihydromyricetin strengthens antiproliferative efficiency of adriamycin via MAPK/ERK and Ca2+mediated apoptosis pathways in MCF-7/ADR and K562/ADR. Journal of cellular physiology. 2018;233(4):3066-3079.

[91] Iqbal STA, Pichiah PBT, Raja S, Arunachalam S. Paeonol reverses adriamycin induced cardiac pathological remodeling through Notch1 signaling reactivation in H9c2 cells and adult zebrafish heart. Chemical research in toxicology. 2019;33(2):312-323.

[92] Suttana W, Mankhetkorn S, Poompimon W, Palagani A, Zhokhov S, Gerlo S, et al. Differential chemosensitization of Pglycoprotein overexpressing K562/Adr cells by withaferin A and Siamois polyphenols. Molecular cancer. 2010;9(1):1-22.

[93] Park EJ, Pezzuto J. Flavonoids in cancer prevention. Anti-Cancer Agents in Medicinal Chemistry (Formerly Current Medicinal Chemistry-Anti-Cancer Agents). 2012;12(8):836-851.

[94] Yuan B, Wang H, Xu JF, Zhang X. Activatable Photosensitizer for Smart Photodynamic Therapy Triggered by Reactive Oxygen Species in Tumor Cells. ACS Applied Materials \& Interfaces. 2020;12(24):26982-26990.

[95] Mohajeri M, Behnam B, Cicero AF, Sahebkar A. Protective effects of curcumin against aflatoxicosis: A comprehensive review. Journal of cellular physiology. 2018;233(4):3552-3577.

[96] Xiao J, Niu G, Yin S, Xie S, Yiqing LI, Nie D, et al. Effects of quercetin in combination with bortezomib or lenalidomide on inhibition of proliferation of HL-60 cells. Journal of Practical
Medicine. 2014;(14):2196-2199.

[97] Domitrović R, Cvijanović O, Pugel EP, Zagorac GB, Mahmutefendić H, Škoda M. Luteolin ameliorates cisplatininduced nephrotoxicity in mice through inhibition of platinum accumulation, inflammation and apoptosis in the kidney. Toxicology. 2013;310:115-123.

[98] Gao AM, Ke ZP, Wang JN, Yang JY, Chen SY, Chen H. Apigenin sensitizes doxorubicin-resistant hepatocellular carcinoma BEL7402/ADM cells to doxorubicin via inhibiting PI3K/Akt/Nrf2 pathway. Carcinogenesis. 2013;34(8):1806-1814.

[99] Arafa ESA, Zhu Q, Barakat BM, Wani G, Zhao Q, ElMahdy MA, et al. Tangeretin sensitizes cisplatin-resistant human ovarian cancer cells through downregulation of phosphoinositide 3-kinase/Akt signaling pathway. Cancer research. 2009;69(23):8910-8917.

[100] Mohana S, Ganesan M, Prasad NR, Ananthakrishnan D, Velmurugan D. Flavonoids modulate multidrug resistance through wnt signaling in P-glycoprotein overexpressing cell lines. BMC cancer. 2018;18(1):1-11.

[101] Lei CS, Hou YC, Pai MH, Lin MT, Yeh SL. Effects of quercetin combined with anticancer drugs on metastasis-associated factors of gastric cancer cells: in vitro and in vivo studies. The Journal of nutritional biochemistry. 2018;51:105-113.

[102] Calatozzolo C, Gelati M, Ciusani E, Sciacca FL, Pollo B, Cajola L, et al. Expression of drug resistance proteins Pgp, MRP1, MRP3, MRP5 AND GST- $\pi$ in human glioma. Journal of neurooncology. 2005;74(2):113-121.

[103] Balyan R, Kudugunti SK, Hamad HA, Yousef MS, Moridani MY. Bioactivation of luteolin by tyrosinase selectively inhibits glutathione S-transferase. Chemico-biological interactions. 2015;240:208-218.

[104] Tong X, Zhao J, Zhang Y, Mu P, Wang X. Expression levels of MRP1, GST- $\pi$, and GSK $3 \beta$ in ovarian cancer and the relationship with drug resistance and prognosis of patients. Oncology letters. 2019;18(1):22-28.

[105] Nakatsuma A, Fukami T, Suzuki T, Furuishi T, Tomono K, Hidaka S. Effects of kaempferol on the mechanisms of drug resistance in the human glioblastoma cell line T98G. Die Pharmazie-An International Journal of Pharmaceutical Sciences. 2010;65(5):379-383.

[106] Kong W, Ling X, Chen Y, Wu X, Zhao Z, Wang W, et al. Hesperetin reverses P\&\#8209;glycoprotein\&\#8209;mediated cisplatin resistance in DDP\&\#8209; resistant human lung cancer cells via modulation of the nuclear factor\&\#8209; $\kappa \mathrm{B}$ signaling pathway. International journal of molecular medicine. 2020;45(4):1213-1224.

[107] Xu X, Li Q, Yu K, Murtaza G, Liu B. Baicalin-induced cytotoxicity and apoptosis in multidrug-resistant MC3/5FU mucoepidermoid carcinoma cell line. Letters in Drug Design \& Discovery. 2019;16(12):1339-1347.

[108] Saeed M, Kadioglu O, Khalid H, Sugimoto Y, Efferth T. Activity of the dietary flavonoid, apigenin, against multidrug-resistant tumor cells as determined by pharmacogenomics and molecular docking. The Journal of nutritional biochemistry. 2015;26(1):4456.

[109] Eneman JD, Potts RJ, Osier M, Shukla GS, Lee CH, Chiu JF, et al. Suppressed oxidant-induced apoptosis in cadmium adapted alveolar epithelial cells and its potential involvement in cadmium carcinogenesis. Toxicology. 2000;147(3):215-228.

[110] Tian B, Lu ZN, Guo XL. Regulation and role of nuclear factor-E2related factor $2(\mathrm{Nrf2})$ in multidrug resistance of hepatocellular carcinoma. Chemico-biological interactions. 2018;280:70-76. 
[111] Celiberto LS, Graef FA, Healey GR, Bosman ES, Jacobson K, Sly LM, et al. Inflammatory bowel disease and immunonutrition: novel therapeutic approaches through modulation of diet and the gut microbiome. Immunology. 2018;155(1):36-52.

[112] Lotito SB, Zhang WJ, Yang CS, Crozier A, Frei B. Metabolic conversion of dietary flavonoids alters their anti-inflammatory and antioxidant properties. Free Radical Biology and Medicine. 2011;51(2):454-463.
[113] Chan LM, Lowes S, Hirst BH. The ABCs of drug transport in intestine and liver: efflux proteins limiting drug absorption and bioavailability. European journal of pharmaceutical sciences. 2004;21(1):25-51.

[114] Oracz J, Nebesny E, Zyzelewicz D, Budryn G, Luzak B. Bioavailability and metabolism of selected cocoa bioactive compounds: A comprehensive review. Critical reviews in food science and nutrition. 2020;60(12):1947-1985. 